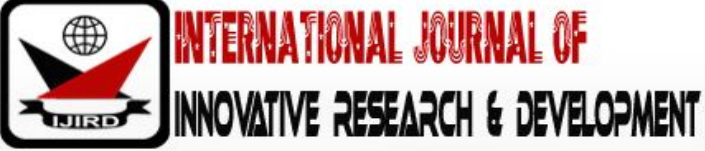

ISSN 2278 - 0211 (Online)

\section{Mothers' Awareness and Level of Knowledge on Skilled Delivery and Its Utilization in Yendi Municipality, Ghana}

\begin{tabular}{c} 
Joseph Balaara Dompielu \\
Senior Health Tutor, Department of Registered General Nursing, \\
Yendi College of Health Sciences, Ghana \\
Michael Wombeogo \\
Senior Lecturer, Department of Public Health, School of Allied Health Sciences, \\
University for Development Studies, Tamale, Ghana \\
\hline
\end{tabular}

\begin{abstract}
:
Background: Skilled delivery is one of the services rendered as part of safe motherhood campaign to prevent maternal and infant deaths. Majority of pregnant women in the Yendi Municipality received antenatal care, but a substantial number do not receive skilled delivery services. The main objective of the study was to find out the awareness and level of knowledge of mothers' on skilled delivery and its utilization in the Yendi Municipality.

Methods: The research was a descriptive cross-sectional survey study among 450 respondents who were selected through the simple random sampling technique in thirty (30) communities to form the sample for the study. Structured questionnaire was used to collect data from 04/ 7/ 2016 - 18/7/2016 for the study. SPSS software package version 21 was used to analyze the data. Chi-square test and Cross-tabulation were the main statistical processes used in analyzing the relationships between the study variables.

Results: Majority (87\%) of respondents was aware of the importance of skilled delivery and 69\% was also aware of risks associated with home delivery. Most of the respondents (72\%) also had confidence in skilled attendants. Findings showed statistically significance between respondents' parity and importance of skilled delivery $(\mathrm{P}=0.005)$. However, more than half of the respondents (51\%) were assisted by TBAs to deliver while $46 \%$ of the respondents indicated that they gave birth in the health facility. Most (53.1\%) respondents also said they fear caesarean section.

Conclusion: Skilled delivery status (46\%) is lower than the WHO 90\% target set since 2004 while TBAs assisted delivery (51\%) is rather high. Thus urgent and appropriate training should be organized for TBAs to sharpen their skills on safe delivery practices in their various communities.
\end{abstract}

Keywords: Skilled delivery, awareness, knowledge, mothers', Yendi municipality, Ghana

\section{Background}

Childbirth is a reproductive right of every woman in their reproductive age and it is very essential for human existence. However, complications that may occur during childbirth can lead to death or disability of a mother or a child (Enchill, 2010).Skilled delivery is one of the services rendered as part of safe motherhood campaign to prevent maternal and infant deaths. Since 2004, WHO advocates for "skilled care at every birth". Thus every woman in labour must be attended to or supervised by a skilled attendant who has been trained to provide quality services to mothers and babies during childbirth. Ensuring quality maternal care services can save the lives of women and newborns.

According to UNICEF (2015), a woman dies from complications in childbirth every minute and about 529,000 each year and the greater majority of these deaths are in developing countries of which Ghana is not an exception. The direct causes of maternal deaths outlined by UNICEF are hemorrhage, infection, obstructed labour, hypertensive disorders in pregnancy, and complications of unsafe abortion.

In Ghana, maternal mortality ratio is still on the increase and remains at an alarming rate of 320/100,000 live births in 2011,324/100,000 live birth in 2012, 321/100,000 live birth in 2013, 322/100,000 live birth in 2014 and 319/ 100,000 live birth in 2015 (WHO, et al., 2015). The statistics above indicate that Ghana has failed to meet the MDG 5 target of 185 maternal deaths per 100,000 by 2015.

An estimated 2,700mothers' life could be saved every year with access to safe clinics and skilled care (WHO, et al., 2012).A woman in Ghana has (1 in 68) a lifetime risk of dying from a maternal cause during childbirth (WHO, et al., 2012). In Ghana, 63 newborns die every day during childbirth which could have been saved through skilled delivery (UNICEF, 2012). The government of Ghana has since 2005 introduced free maternal health policy that makes maternal health services free of charge in all health institutions. Furthermore, the introduction of a National Health Insurance Scheme in all districts in Ghana was expected to reduce the financial burden on pregnant women in order to increase access to skilled 
birth care services (GHS Report, 2007). However, these interventions by the government of Ghana have not yielded the needed results.

The antenatal (ANC) coverage in Ghana was 97\% and skilled delivery was 74\% in 2014 (GDHS, 2014). In Northern region, skilled delivery was 53.3\% in 2014 and 52.8\% in 2015 (GHS, 2015).

Statistics available at the Yendi Municipal Health Directorate (YMHD) indicate that skilled delivery rate did not meet the $90 \%$ target set by WHO and adopted by Ghana Health Service. Also, there is an increasing trend in maternal mortality. The Municipality performance in ANC coverage, skilled delivery and maternal deaths recorded is as follows;

\begin{tabular}{|c|c|c|c|}
\hline Year & ANC Coverage & Skilled delivery & Maternal death \\
\hline 2012 & $49.7 \%$ & $27.2 \%$ & 6 \\
\hline 2013 & $97.4 \%$ & $58.3 \%$ & 7 \\
\hline 2014 & $130.4 \%$ & $84.1 \%$ & 8 \\
\hline 2015 & $121.2 \%$ & $84.3 \%$ & 14 \\
\hline
\end{tabular}

Table 1

Source: YMHD Report, 2015

The over 100\% ANC coverage in 2014 and 2015 are due to more ANC registrants recorded than the denominator given to the district by the Northern Regional Health Directorate for the 2014 and 2015 performance year. Thus the skilled delivery figures recorded for 2014 and 2015 are likely to be less than what is recorded if calculation of the skilled delivery for Yendi Municipal was based on 100\% ANC coverage.

Looking at the figures, the trend of skilled delivery in the Yendi Municipality has seen an increased since 2012 to 2015. Despite the gains made since 2012, the target of (90\%) skilled delivery is not met.A good number (36.9\%) of expectant mothers who received ANC services in 2015 did not seek skilled delivery (YMHD Report, 2015).

Also, maternal mortality rate in the Yendi Municipality has seen an increasing trend with a ratio of 137/100,000 per live births in 2013 and 143/ 100,000 per live births in 2014 (YMHD Report, 2015).Some expectant mothers probably are not aware of the importance of skilled delivery and do not consider the consequences of not utilizing skilled delivery services. Current strategies to increase skilled delivery among expectant mothers depend on mothers attending ANC and knowing the importance of skilled delivery (YMHD Report, 2015). Therefore, based on the above the mother with low level of awareness and knowledge on skilled delivery is more likely not to utilize it during delivery hence the need for the study.

\section{Methodology}

\subsection{Study Setting}

The Yendi Municipal Assembly was established in 1988 by PNDC Law 207, Act 462, and LI 1443. It was elevated to a Municipality in 2007. The Municipality is one of the fifty-four (54) Municipal Assemblies in the country and the only Municipality in the Eastern corridor of the Northern Region. It is the capital of the Dagbon Kingdom (YMA report, 2014).

The Municipal shares boundaries with six (6) other District Assemblies; to the East; Saboba District, Chereponi District and Zabzugu District, to the South Nanumba North District, to the North Gushegu District and Mion District to the West (GSS, 2010). The Municipality is strategically located at the center of the Eastern Corridor of the northern region; it has a landmass of 1,446.3 sq km.(GSS, 2010). It is about $90 \mathrm{~km}$ from the Northern Regional capital, Tamale (YMA report, 2014).

The population of the Yendi Municipality is about 136,434 projected from 2010 population and Housing Census. The Municipality has a number of health facilities including; Yendi Municipal Hospital which is a referral hospital located within the Yendi Township, health centers and clinics located at Bunbonayili, Gnani, Adibo, Community Health and Planning Services (CHPS) at Sunson, Dabogni and Kuni (YMA report, 2014 and YMHD Report, 2014).

\subsection{Study Design}

The study was conducted using a descriptive cross-sectional survey design that made use of quantitative method of data collection. The data was collected to answer questions by ascertaining mothers' awareness and level of knowledge on skilled delivery and their choice of place of delivery. A structured questionnaire was used to gather information from mothers' with very young children (1 day - 12 months) and has been living in Yendi Municipality for at least two years.

\subsection{Sample Size Determination}

A sample size of 450 mothers who have very young children (1 day to 12 months of age) was used for the study. This sample size was arrived at through the cluster sample size estimation method (Lwanga \& Lemeshow, 1991). The sample size was estimated using the following assumptions:

- National skilled delivery coverage of 74\% (GDHS, 2014)

- Level of statistical confidence of the estimate of $95 \%$

- Desired precision of the estimate of $\pm 5 \%$

- Magnitude of differences of coverage among and within the clusters of 1.5.

- With reference to these assumptions, the sample size was calculated using the formula: $\mathrm{N}=\mathrm{De} \times \mathrm{Z}^{2} \times \mathrm{p}(1-\mathrm{p})$

$\mathrm{d}^{2}$ 
Where:

$\mathrm{N}$ =sample size

De $=$ design effect, the ratio between the variance from the cluster design to the variance that would be obtained from a simple random sampling

$\mathrm{Z}=$ the certainty wanted expressed in the percentage point of normal distribution corresponding to the 2-sided level of significant

$\mathrm{P}=$ Skilled delivery coverage

$\mathrm{d}=$ the desired width of the confidence interval

Assuming a design effect of 1.5 ( $\mathrm{De}=1.5$ ), confidence level of $95 \%$ with an alpha level of $5 \%$, then $\mathrm{Z}=1.96$, skilled delivery coverage $74 \%(p=0.74)$ and a desired width of the confidence interval of $\pm 5(\mathrm{~d}=0.05)$, the sample size was calculated as follows:

$\mathrm{N}=1.5 \times \frac{(1.96)^{2} \times 0.74(1-0.74)}{(0.05)^{2}} \mathrm{~N}=1.5 \times \frac{3.8416 \times 0.74 \times 0.26}{0.0025}$

$\mathrm{N}=1.5 \times \underline{0.73912384}$

$$
0.0025 \quad \mathrm{~N}=1.5 \times 295.65 \mathrm{~N}=443.48 \approx 450
$$

Since thirty clusters were used for the study, the sample size for each cluster was; $450 / 30=15$

\subsection{Sampling Procedure}

Yendi Municipality has (6) sub-districts. To ensure fair representation of participants in the study area, five communities each were selected from the six sub-districts making a total of thirty (30) communities.

After determining the sample size, five (5) communities each were selected from the six (6) sub-districts to form the clusters for the study. The six sub-districts are; Yendi Central, Yendi East, Yendi West, Adibo, Bumbon and Gnani. The procedure was done by first writing the names of the communities in each sub-district on pieces of paper, folded these papers and put them into a basket. These papers were shuffled and five of them were selected without looking into the basket, and replacing the piece of paper selected back into the basket in order to give equal chances to other communities names to be selected as well. This was done for all the six sub-districts to select the communities for the data collection.

\subsection{Data Collection Instrument and Procedures}

Structured questionnaire was used to collect data from the respondents. This questionnaire type allows less involvement of the researcher during administration of the instrument and high level of involvement of the interviewee who is answering the questionnaire. Structured questionnaire usually ask direct and closed ended questions.

Upon reaching each of the selected community, the central point was located. A pencil was spun and the direction of the tip was followed. The first house in that direction was the first house entered for data collection. Upon entry into the house, a mother who met the criteria was interviewed upon agreeing to participate in the study. A house with more than one eligible mother, several "NOs" and one "YES" were written on pieces of papers, summing up to their number and tossed. The one who picked the "YES" was interviewed. While coming out, the house that the interviewer faces was the next house to enter. If there was no house in front upon exit, the pencil was spun again and the direction followed.

However, if the target number for that particular community was not found, simple random sampling was used again on the other communities until the proportion for that sub-district was attained.

\subsection{Data Processing and Analysis}

Data collected was assembled and checked for completion. Thus each questionnaire was examined to be sure that it was properly administered and all the items on each questionnaire were answered. Afterwards, the data was entered into a template that had been designed for entry and analysis using the SPSS software package windows version 21.Data entry, cleaning, processing, preliminary analysis was done by the researchers with assistance from a statistician and the final write-up was done by the researchers. This SPSS software enables the researchers to acquire relevant percentages and frequencies which made interpretation of the data more reliable and comprehensive. Where necessary, tables, pie charts and graphs were used to give a more pictorial view of the result of the research findings.

\subsection{Ethics Approval and Informed Consent}

An introductory letter from the Department of Public Health, University for Development Studies was obtained to enable researchers visit the communities for the data collection. Also, permission letter was obtained from Yendi Municipal Health Directorate before the researchers visited the communities for the study. The purpose of the research was discussed with the community leaders and other significant people whose support and assistance were needed. Participation was completely voluntary. Verbal consent was sought from each individual participant before the administration of each questionnaire.

\section{Results}

\subsection{Demographic Characteristics of Respondents}

The socio-demographic background of the respondents is shown in Table1 with the following variables; age, sex, marital status, ethnicity, religion, education, occupation, health care and distance to health centres. As shown in Table 1, 
ages 20-29 years constituted the modal group whilst only $13(2.9 \%)$ and 31 (6.9\%) respondents were within each one of the ages of 15-20 and 40+years respectively. More so, 44.7\% of the respondents were within the age range of 30-39 years. Majority of the respondents 393 (87.3\%) were married, 47 (2.9\%) respondents were single or in consensual relationship; thus they are in a relation and agreed to stay together but not formally recognized by their families, $5(1.1 \%)$ respondents were separated from their husbands, $4(0.9 \%)$ respondents were widowed whilst $1(0.2 \%)$ respondents said they were divorced from their husbands. From the Table 1 also, majority of the respondents (61.1\%) were Dagomb as, $34.7 \%$ respondents were Konkomb as, $0.4 \%$ respondents were Nanumb as whilst 3.8\% respondents said they were Ewes. Furthermore, by religion, $67.3 \%$ of them were Moslems, 20\% respondents were Christians, and 12.7\% respondents believed in African Traditional Religions (ATRs). On the issue of educational status of respondents, findings revealed that majority of the respondents (81.1\%) had no formal education, 8.4\% respondents said they had Junior High School (JHS)/ Middle School education, 8.2\% respondents had Primary education, 2\% respondents had SHS education with only $0.2 \%$ respondents having tertiary education. Majority of the respondents (67.8) were involved in farming, $22.2 \%$ respondents were involved in petty trading, 3.8\% respondents were Artisans, $0.4 \%$ respondents were salaried workers whilst $5.8 \%$ respondents were unemployed.

Table 1 further revealed that 73.3\% respondents' husbands had no formal education, $10.7 \%$ respondents husbands had Senior High School (SHS) education, 9.3\% respondents husbands had JHS/ Middle School education and $3.3 \%$ respondents each had Primary and tertiary education. Majority of respondents' husbands were farmers $(78.4 \%)$, traders (2.7\%), salaried workers (2.9\%) and students (16\%).

From Table 1, respondents were asked to indicate the age of their current child in months and majority of the respondents 243 respondents representing 54\% said their child aged 9 months or more, 85 respondents representing $18.9 \%$ said their child aged between 1-6 months, 83\% respondents representing $18.4 \%$ said their child aged 1-9 months whilst 39 respondents representing $8.7 \%$ said their child aged between 1-3 months.

\begin{tabular}{|c|c|c|c|}
\hline \multicolumn{2}{|c|}{ Variable } & Frequency (450) & Percent (\%) \\
\hline \multirow[t]{5}{*}{ Age } & $10-19$ & 13 & 2.9 \\
\hline & $20-29$ & 205 & 45.6 \\
\hline & $30-39$ & 201 & 44.7 \\
\hline & $40+$ & 31 & 6.9 \\
\hline & Single & 47 & 2.9 \\
\hline \multirow[t]{6}{*}{ Marital } & Married & 393 & 87.3 \\
\hline & Divorce & 1 & 0.2 \\
\hline & Separated & 5 & 1.1 \\
\hline & Widow & 4 & 0.9 \\
\hline & Dagomba & 275 & 61.1 \\
\hline & Konkomba & 156 & 34.7 \\
\hline \multirow[t]{3}{*}{ Ethnicity } & Nanumba & 2 & 0.4 \\
\hline & Ewe & 17 & 3.8 \\
\hline & Islam & 303 & 67.3 \\
\hline \multirow[t]{4}{*}{ Religion } & Christianity & 90 & 20.0 \\
\hline & ATRs & 57 & 12.7 \\
\hline & No formal education & 365 & 81.1 \\
\hline & primary school & 37 & 8.2 \\
\hline \multirow[t]{5}{*}{ Education } & JHS/ Middle school & 38 & 8.4 \\
\hline & SHS & 9 & 2.0 \\
\hline & Tertiary & 1 & 0.2 \\
\hline & Public servant & 2 & 0.4 \\
\hline & Petty trading & 100 & 22.2 \\
\hline \multirow[t]{5}{*}{ Occupation } & Farming & 305 & 67.8 \\
\hline & Artisan & 17 & 3.8 \\
\hline & Unemployed & 26 & 5.8 \\
\hline & No formal education & 330 & 73.3 \\
\hline & Primary school & 15 & 3.3 \\
\hline \multirow[t]{4}{*}{ Husb. Education } & JHS/ Middle school & 42 & 9.3 \\
\hline & SHS & 48 & 10.7 \\
\hline & Tertiary & 15 & 3.3 \\
\hline & Farming & 353 & 78.4 \\
\hline \multirow[t]{4}{*}{ Husb. occupation } & Trading & 12 & 2.7 \\
\hline & Public servant & 13 & 2.9 \\
\hline & Students & 72 & 16.0 \\
\hline & $1-3$ & 39 & 8.7 \\
\hline \multirow[t]{3}{*}{ Age of child (months) } & $1-6$ & 85 & 18.9 \\
\hline & $1-9$ & 83 & 18.4 \\
\hline & $9+$ & 243 & 54.0 \\
\hline
\end{tabular}

Table 2: Socio-Demographic Characteristics of Respondents 
The place where respondents' last child was delivered is shown in Figure 1. From Figure 1, 209 respondents representing $46 \%$ indicated that they gave birth to their last child in the health facility, 229 respondents representing $51 \%$ said they were assisted by TBAs to deliver whilst 12 respondents representing 3\% said they were assisted by their relatives and family members to deliver at home.

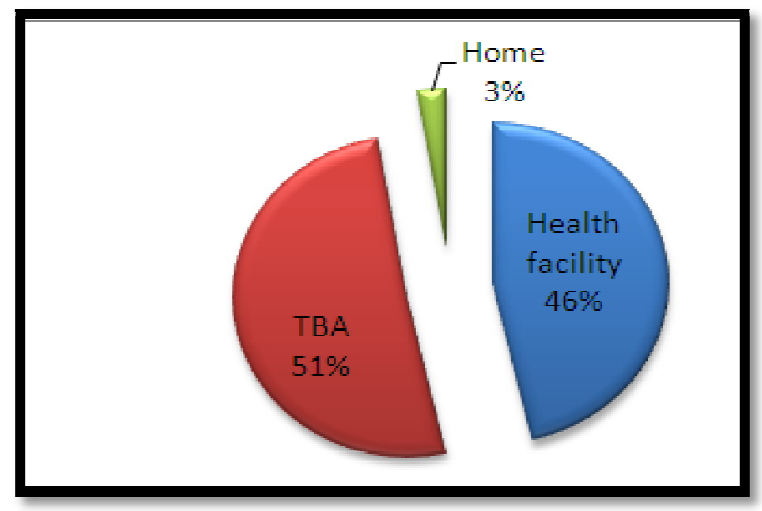

Figure 1: Place of Delivery of Last Child

Cross tabulation of parity and importance of skilled delivery is shown in Table 2.From the results showed in the cross tabulation in Table 2, a Chi-square value of ( $\mathrm{P}<0.001$ ) was found showing a clear statistically significance between respondents parity and their knowledge on skilled delivery. From the results, $85.5 \%$ of respondents with para 1-2 (women who have given birth to 1-2 children) said yes to the statement that they have knowledge on importance of skills delivery, 87.2\% respondents with para1-4 said they have knowledge on importance of skilled delivery, $87.1 \%$ respondents with para 1-6 said they have knowledge on importance of skilled delivery whilst 87.5\% respondents with more than 6 children said they knew the importance of skilled delivery.

\begin{tabular}{|c|c|c|c|}
\hline \multirow{2}{*}{ Parity } & \multicolumn{2}{|c|}{ Importance of Skilled delivery } & \multirow{2}{*}{ P-value } \\
\cline { 2 - 3 } & Yes & No & \\
\hline $1-2$ & $85.5 \%$ & $14.5 \%$ & \\
\hline $1-4$ & $87.2 \%$ & $12.8 \%$ & \\
\hline $1-6$ & $87.1 \%$ & $14.9 \%$ & \\
\hline $7+$ & $87.5 \%$ & $12.5 \%$ & 0.001 \\
\hline
\end{tabular}

Table 3: Cross Tabulation of Parity and Importance of Skilled Delivery

Awareness of the importance of skilled delivery by respondents is shown in Figure 2. From Figure 2, majority of the respondents representing $87 \%$ said they were aware of the importance of skilled delivery whilst $13 \%$ respondents however claimed that they were not aware of the importance of skilled delivery.

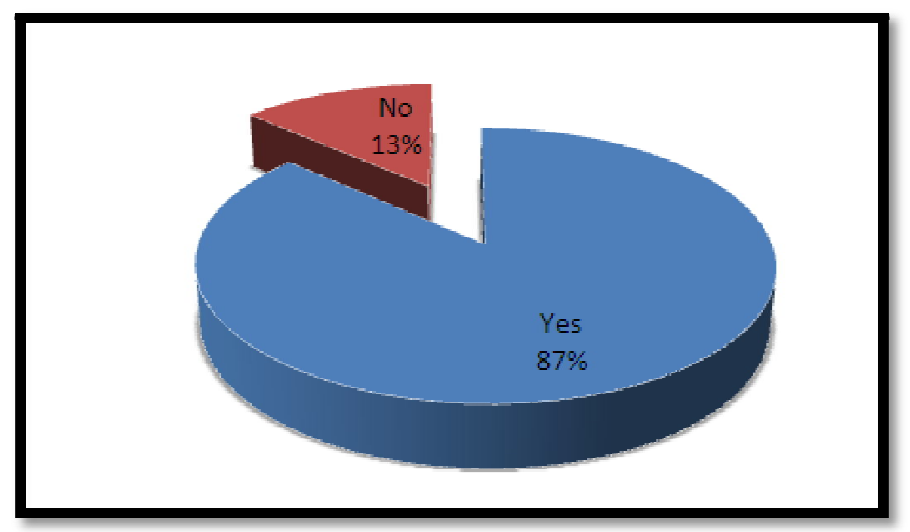

Figure 2: Awareness of the Importance of Skilled Delivery

Respondents' awareness of risks associated with home delivery is presented in Figure 3. From Figure 3, majority, $69 \%$ respondents stated that they were aware of the risk associated with home delivery whilst $31 \%$ respondents said they were not aware of the risk associated with home delivery. 


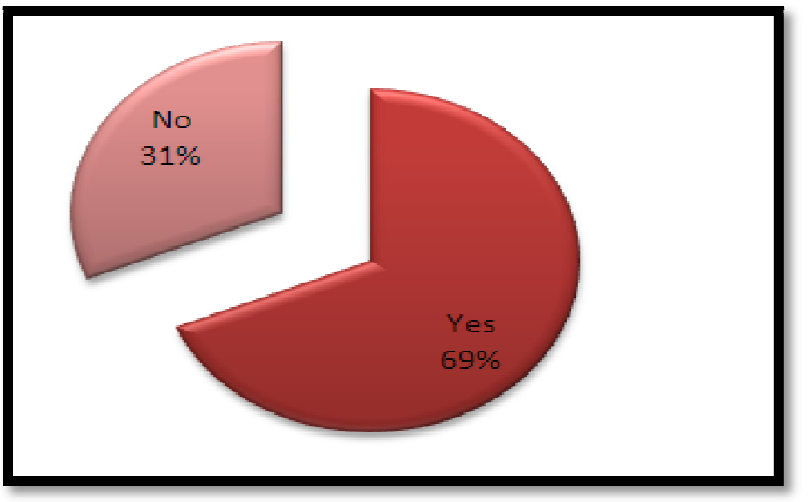

Figure 3: Awareness of Risks Associated with Home Delivery

The Fear that respondents have about certain skilled delivery process is indicated in Table 3. From Table 3, respondents were asked whether they had any fear for the following processes of health facility delivery as at the time they gave birth to their last child and 63 respondents representing $14 \%$ said they feared been referred to go to a far place to delivery, 132 (29.4\%) respondents said they never had any fear for health facility delivery, 239 (53.1\%) respondents said they feared being operated upon whilst they rest are shown in the Table 3 below.

\begin{tabular}{|c|c|c|}
\hline Fear of Skilled Delivery Process & Frequency & Percent \\
\hline Hospital setting & 5 & 1.1 \\
\hline Referral & 63 & 14.0 \\
\hline Injection & 7 & 1.6 \\
\hline Caesarean section & 239 & 53.1 \\
\hline Medicine & 2 & 0.4 \\
\hline Position taken during delivery & 2 & 0.4 \\
\hline I had no fear & 132 & 29.4 \\
\hline Total & 450 & 100.0 \\
\hline
\end{tabular}

Table 4: Fear of Certain Skilled Delivery Process

Concerning how respondents assessed the confidence of service providers during delivery, respondents were asked to indicate the service provider they had confidence in their service at the time they gave birth to their last child and as shown in Figure 4, majority (72\%) said they had confidence in skilled attendants, 13\% respondents identified religious figures such as the Pastors, Mallams and Priest, 11\% respondents identified the TBAs in their communities whilst 6\% respondents said they were confident in their relatives.

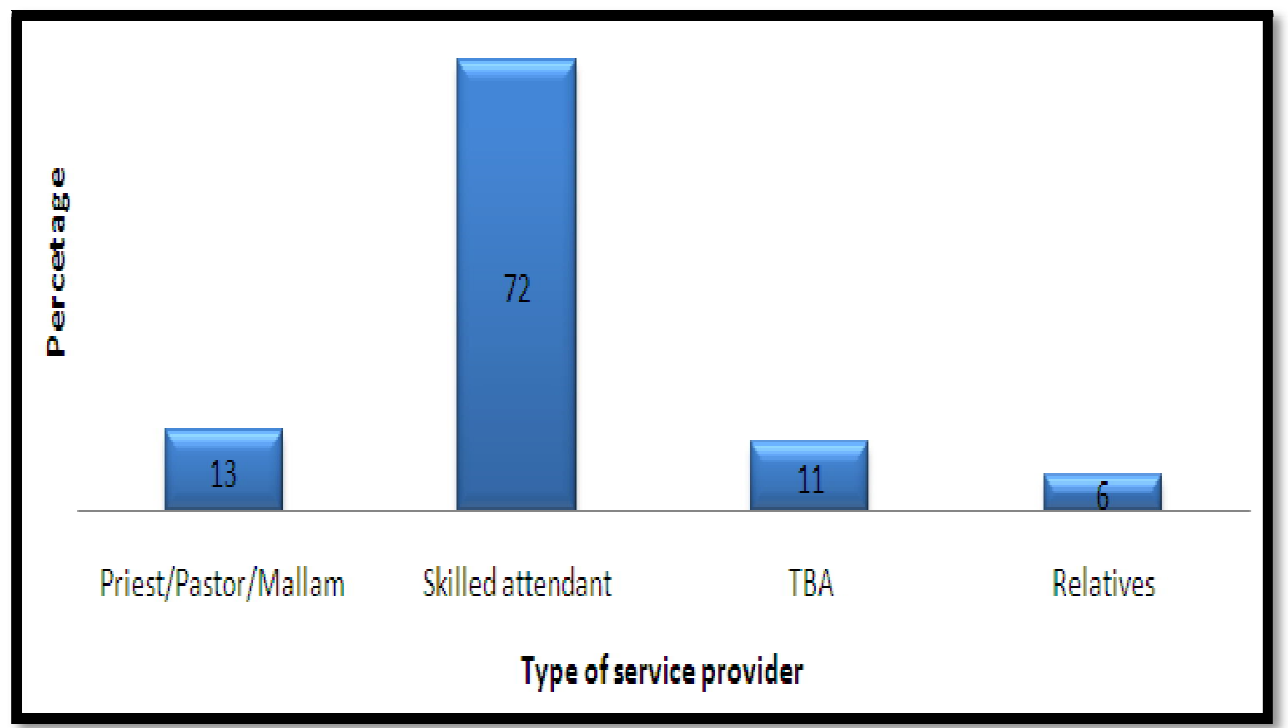

Figure 4: Confidence in Service Provider

\section{Discussion}

The study assessed mothers' awareness and level of knowledge on skilled delivery and its utilization in Yendi Municipality. The birth place of respondents' last child was asked and 209 respondents (46\%) indicated that they gave birth in the health facility; majority 229 respondents (51\%) said they were assisted by TBAs to deliver whilst 12 respondents(3\%) said they were assisted by their relatives and family members to deliver at home. 
Nakua etal., (2015) in Amansie West District, Ghana found in their study, a total of 391 mothers had attended an antenatal care clinic at least once for their most recent birth and most of them $42.3 \%$ had unskilled deliveries. Reasons given for the use of unskilled birth attendants during delivery were: insults from health workers (23.5\%), unavailability of transport (21.9\%), and confidence in traditional birth attendants (17.9\%); only 7.4\% reported to have had sudden labour. Other factors associated with the use of unskilled birth attendants during delivery included: lack of partner involvement, lack of birth preparedness and lack of knowledge of the benefits of skilled delivery. Nakua etal., (2015) also found in their study that TBAs in the district who are perceived by expectant mothers to be "good" and whose practices may be culturally sensitive and consistent with the belief system of the rural woman were some of the reasons they go to deliver by them.

A study by Crissman etal.,(2013) found in Akwatia District- Ghana, that about 61\% of their participants agreed to have experienced one health facility delivery under the supervision of a skilled midwife while some $11 \%$ reported to have also gone through unskilled delivery at the house where a TBA supervised the delivery for at least one of their children. All the 85 pregnant women age 18-41 years involved in Crissman etal., (2013) qualitative study cited their decision to deliver at the health facility to safe guard them from encountering complications during delivery.

Parity and importance of skilled delivery was analyzed. The results $(\mathrm{P}<0.001)$ was found showing a clear statistically significance between respondents parity and their knowledge on skilled delivery. From the results, $85.5 \%$ of respondents with para 1-2 said that they have knowledge on importance of skills delivery, $87.2 \%$ respondents with para14 said they have knowledge on importance of skilled delivery, 87.1\% respondents with para 1-6 also said they have knowledge on importance of skilled delivery whilst $87.5 \%$ respondents with more than 6 children said they knew the importance of skilled delivery. This indicates that women who delivered one child and above have gone through pregnancy and delivery experiences thereby acquiring knowledge on the importance of skilled delivered.

Awareness of the importance of skilled delivery by respondents was examined. Majority of the respondents representing $87 \%$ said they were aware of the importance of skilled delivery whilst $13 \%$ respondents however claimed that they were not aware of the importance of skilled delivery.

Respondents' awareness of risks associated with home delivery was asked for. Majority, $69 \%$ respondents stated that they were aware of the risk associated with home delivery whilst $31 \%$ respondents said they were not aware of the risk associated with home delivery.

However, Nakua etal., (2015) in Ghana found that despite high ANC attendance, participants reported poor knowledge of risks associated with pregnancy (44.5\%). Although most (83.6 \%) participants claimed knowing the importance of skilled delivery, $54.8 \%$ had ever delivered at least one of their children without using a skilled care and $42.3 \%$ reported delivering their most recent child without skilled care.

The Fear that respondents have about certain skilled delivery process was verified. Respondents were asked whether they had any fear for the following processes of health facility delivery as at the time they gave birth to their last child and 63 respondents representing 14\% said they feared been referred to go to a far place to delivery, $132(29.4 \%)$ respondents said they never had any fear for health facility delivery, 239 (53.1\%) respondents said they feared being operated upon whilst they rest feared medicine intake $(0.4 \%)$, position taken during delivery $(0.4 \%)$ and $29.4 \%$ of respondents had no fear of health facility delivery processes. The fear of surgical operation during delivery may lead to most pregnant women refusing to seek skilled delivery services.

Concerning how respondents assessed the confidence of service providers during delivery, respondents were asked to indicate the service provider they had confidence in their service at the time they gave birth to their last child. Majority (72\%) said they had confidence in skilled attendants, 13\% respondents identified religious figures such as the Pastors, Mallams and Priest, and 11\% respondents identified the TBAs in their communities whilst $6 \%$ respondents said they were confident in their relatives. This findings show that most expectant mothers have trust in health care skilled attendants who can save their life as well as their babies.

\section{Limitation of the study}

Recall bias - The recall period in the study was maintained at 12 months, but this was still a sufficiently long period to affect recall bias.

\section{Conclusion}

Despite respondents having high awareness (87\%) on importance of skilled delivery and risk awareness (69\%) associated with home delivery most of them did not seek skilled delivery during their recent child birth. Skilled delivery status (46\%) is lower than the WHO 90\% target set since 2004 while TBAs assisted delivery (51\%) is rather high. Thus urgent and appropriate training should be organized for TBAs to sharpen their skills on safe delivery practices in their various communities while the Municipality put in measures to improve skilled delivery uptake.

\section{Acknowledgements}

The authors are grateful to all heads of households who gave the researchers the permission to interview respondents for this study. We are also grateful to the following people who supported the study and offered various helpful advice and inputs especially during the data collection phase of the study: Municipal Health Director and Midwives/ Community Health Nurses/ Nurse Assistant Clinical in Yendi Municipal 


\section{Funding}

The authors funded the study. No external funding.

8.1. Availability of Data and Materials

Please contact author for data request.

\subsection{Authors' Contributions}

The authors conceived the topic, designed and conducted the study. The authors collected the data, performed the analysis and the discussion of the results. The planning, writing and revision of the manuscript was done by both of them. Both authors have read and approved the final version of the study.

\subsection{Authors' Information}

Joseph Balaara Dompielu (JBD) is a Health Tutor with the Yendi College of Health Sciences, Ministry of Health Ghana. He holds a Diploma in Registered General Nursing, B.Ed. in Health Science and MPhil in Community Health and Development.

Michael Wombeogo (MW) is a Senior Lecturer with the Department of Public Health, School of Allied Health Sciences, UDS, and Tamale Ghana. He holds DLit Et Phil (DS), PhD in Rural Health development, IPN, MSc in Public Health, MA, HPE, MA, DS and ADPM.

8.4. Competing Interests

The authors declare that they have no competing interests.

8.5. Consent for Publication

Individual respondents consent to participate in the study

8.6. Ethics Approval and Consent to Participate

Permission from health system and university authorities as well as individuals consent

\subsection{Authors' Affiliations}

- Yendi College of Health Sciences, Ministry of Health - Ghana

- Department of Public Health, School of Allied Health Sciences, University for Development Studies, Ghana

\section{References}

i. $\quad$ Crissman, P., H., Crespo, K., Engmann, E., C., Adanu, M., R., Nimako, D., and Moyer, A., C., (2013),Shifting norms: pregnant women's perspectives on skilled birth attendance and facility-based delivery in rural Ghana. African Journal of Reproductive Health March 2013; 17(1): 15

ii. Enchill, E., C., (2010). Factors influencing Skilled Delivery in the Asante Akim North Municipality of Ghana, Kwame Nkrumah University of Science and Technology, Press Kumasi, Ghana

iii. Ghana Demographic and Health Survey Report, 2014

iv. Ghana Health Service Annual Report (2007). Reproductive and Child Health Unit, Public Health Unit, Ghana

v. Ghana Health Service Family Health Division Report, 2015

vi. Ghana Statistical Service Report, 2010

vii. Lwanga S. K. and Lemeshow S. Sample Determination in Health Studies; A Practical Manual. Geneva: World Health Organization; 1991.

viii. Nakua, K., E., Sevugu, T., J., Dzomeku, M., V., Otupiri, E., Lipkovich, R., H., and Owusu-Dabo, E., (2015), Home birth without skilled attendants despite millennium villages' project intervention in Ghana: insight from a survey of women's perceptions of skilled obstetric care. BMC Pregnancy and Childbirth (2015) 15:243.

ix. UNICEF Report (2015). Maternal and newborn health

x. UNICEF, World Health Organization, the World Bank, \& United Nations Population Division (2012); Levels and Trends in Child Mortality Report 2015: Estimates Developed by the UN Inter-agency Group for Child Mortality Estimation. New York: UNICEF.

xi. WHO (2004); Making Pregnancy Safer: the critical role of the skilled attendant. Department of Reproductive Health and Research; Geneva WHO

xii. WHO, UNICEF, UNFPA, World Bank Group \& the United Nations Population Division (2012); Trends in Maternal Mortality: 1990 - 2015. Estimates by WHO, UNICEF, UNFPA, World Bank Group and the United Nations Population Division; Geneva: WHO

xiii. World Health Organization (2015); Trends in Maternal Mortality: 1990 to 2015: Estimates by WHO, UNICEF, UNFPA, the World Bank and the United Nations Population Division. Geneva: WHO

xiv. Yendi Municipal Assembly Report, 2014

xv. Yendi Municipal Health Directorate Annual Report, 2015

xvi. Yendi Municipal Health Directorate Report, 2014 